\title{
Increased reliability, manoeuvrability and durability of steam turbines through the implementation of the generator driving mode
}

\author{
E. K. Arakelyan, A. V. Andryushin \& K. A. Andryushin \\ National Research University "Moscow Power Engineering Institute", \\ Russia
}

\begin{abstract}
The problem of power backup for steam turbines when passing through the long load failures, is particularly relevant at present. It is caused by stricter requirements of dispatching services of power supply systems to reliability, manoeuvrability and cost-effectiveness. Alternative ways of the units transition to night time backup with the complete removal of the active load are the stopstart mode and generator driving mode (SSM and GDM). The generator driving mode is understood as its work without supply of operational steam to the head part of the turbine without disconnection of the generator from the network. Generator works as the engine, consuming from a network the active power required to cover mechanical and ventilation power losses in the turbine and electric and ventilation losses in the generator. The purpose of the present article is to summarize the results of these studies so as to identify the optimum schemes of GDM implementation process in terms of manoeuvrability, reliability and cost-efficiency. The technique of GDM application will be analyzed for the first time for steam turbines of combined cycle gas turbine units. As a result, it has been shown that GDM application for steam turbines has a number of operational advantages in comparison with SSM: significant increase of manoeuvrability and reliability of the equipment during operation in the semipeak mode; durability of turbine elements increases thanks to the minimum amplitude of thermal tension; cyclic temperature tensions decrease, which removes the limits of numbers of transition into backup mode for turbine unit.

Keywords: generator driving mode, reliability, maneuverability, costeffectiveness, combined cycle, gas turbine units.
\end{abstract}




\section{Introduction}

The problem of power backup for steam turbines when passing through the long load failures, for example, at night, always existed, but it is particularly relevant at present. It is caused by stricter requirements of dispatching services of power supply systems to reliability, manoeuvrability and cost-effectiveness during the work of power plants in the market of the electric power and output. The existing practice of power units' transition in the mode with the minimum load within the adjustment range is not always justified in terms of cost-effectiveness and reliability.

Alternative ways of the units' transition to night time backup with the complete removal of the active load are the stop-start mode (SSM) and generator driving mode (GDM). Non-availability of expenses and operations of the stopped equipment - the main advantage of SSM, however, at the same time reliability of operation and manoeuvrability of the equipment reduces dramatically.

The generator driving mode is understood as its work without supply of operational steam to the head part of the turbine through its steam inlet parts. Turbogenerator is not disconnected from the network; generator works as the engine with synchronous frequency of rotation, consuming from a network the active power, required to cover mechanical and ventilation power losses in the turbine and electric and ventilation losses in the turbogenerator. Some steam is supplied to turbine to cool down the flow part of cylinders, and rated vacuum is kept in condenser, which ensures the steam entering the condenser followed by its condensation.

For synchronous turbogenerator this mode nears the idle operation mode with respect to the active power output [1-3].

\section{The use of GDM at steam turbines of TPP}

One of the major advantages of GDM as compared with SSM is the considerable increase of service life of turbine unit components due to the minimum amplitude of thermal tensions during the whole cycle of load change, inclusive of removal of load and transition with the subsequent load increase up to the maximum load. The decrease of cyclic temperature tensions when using GDM removes the limits on quantity of turbine unit, which is put into standby for periods of daily load failures [10].

When operating in GDM the specific for turbine hot start and considerable $\left(140-200^{\circ} \mathrm{C}\right.$ ) and sharp (with speed $18-20^{\circ} \mathrm{C} / \mathrm{min}$.) temperature changes downstream of the control stage are excluded, in the intermediary and last stages of HP, IP and LP cylinder. The higher level of steam temperatures downstream of control stage and lower cooling of HP cylinder stages in the area of the first stages at turbines start is explained with non-availability of stages of turn-over, spin up, idle operation, synchronization and generator entering the grid with low steam flow rate, which considerable speeds up the process of turbine loading. The possibility to control the temperature in the flow part of turbine by means of 
varying the parameters and flow rates of cooling steam (steam for cooling of turbine flow part) creates the favorable conditions for further turbine startup.

Fuel consumption for GDM comprises the following components:

- for preparation of steam for turbine end seals, for operation of ejector unit and for cooling of turbine flow part;

- for production of electric power, required for rotation of turbogenerator and for auxiliary electrical purposes.

One of the main parameters that characterizes operation of turbogenerators in GDM, is the power consumed by generator from grid. It is spent to cover the output losses in turbine and generator, and with the constant flow rates of steam to turbine end seals it depends on pressure in the condenser and flow rates of cooling steam. Based on statistical processing of results of great amount of experiments at the actual facilities for turbines K-100, T-100 and K-200 the equations are found for dependence of generator power on the specified factors [1]:

$$
\begin{gathered}
\mathrm{N}_{\text {ГМР }}=1.3-0.41 D_{1}-0.137 D_{2}+200 p_{K}, \mathrm{~K}-100 \\
\mathrm{~N}_{\text {ГМР }}=2.09-0.021 D_{1}-0.206 D_{2}+110.5 p_{K}, \mathrm{~T}-100 \\
\mathrm{~N}_{\text {ГМР }}=2.04-0.407 D_{1}-0.099 D_{2}+309.8 p_{K}, \mathrm{~K}-200
\end{gathered}
$$

where $D_{1}, D_{2}$ - flow rates of cooling steam, $\mathrm{kg} / \mathrm{s} ; p_{K}$-pressure in the condenser, MPa.

Based on consolidation of experimental measurements and theoretical prediction to analyze consumption of reference fuel $\mathrm{n}$ GDM depending on turbine power and pressure in condenser the following equation was obtained [1]:

$$
\begin{gathered}
B_{O \Pi T}^{M P}=0.34+0.36 N_{\Pi P}+0.32 N_{\Pi P}^{2}+\left(0.26 N_{\Pi P}+0.12 N_{\Pi P}^{2}\right) \\
x\left[1.5\left(p_{K \Pi P}-0.4\right)+1.25 x\left(p_{K \Pi P}-0.4\right)^{2}\right]
\end{gathered}
$$

where $B_{O I T}^{M P}$ - flow rate of reference fuel (ref. fuel t/h) in GDM at optimum conditions of its operation (based on pressure in condenser, flow rates and parameters of cooling steam); $N_{\Pi P}=N_{H} / 100$ - corrected rated power of turbine, $\mathrm{MW} ; p_{R \Pi P}=100 p_{K}$ - corrected pressure in condenser, MPa.

Consolidation of calculated and experimental research permitted to determine the general arrangement scheme of cooling steam supply into flow part of steam turbines of miscellaneous output to ensure the temperature condition of turbine metal to be to the maximum extent closer to the nominal:

- $\quad$ HP cylinders (K-800, K-300, K-200) operate in steam-less generator driving mode with counterflow scheme of steam movement, supplied from the front 
end seals with discharge either via drainage lines of stop valves, or via special suction line into condenser;

- $\quad$ LP blades, for which the ratio $1 / \mathrm{d}$ is not big, may operate in steam-less mode, since for their cooling the suction of steam via end seals is sufficient; for further stages of IP and LP cylinders the optimum is the steam supply of the due parameters into the middle part of IP cylinder and to the receiver pipes of LP cylinder in the amounts, defined either experimentally, or by mathematic modeling;

- $\quad$ to cool the last stage and exhaust nozzle of LP cylinder it is recommended to make the injection of hot condensate with temperature over 60 degrees Celsius into the exhaust nozzle in the amount, determined experimentally.

To illustrate, Figure 1 shows the simplified scheme of steam supply for transfer of turbine K-200 into GDM.

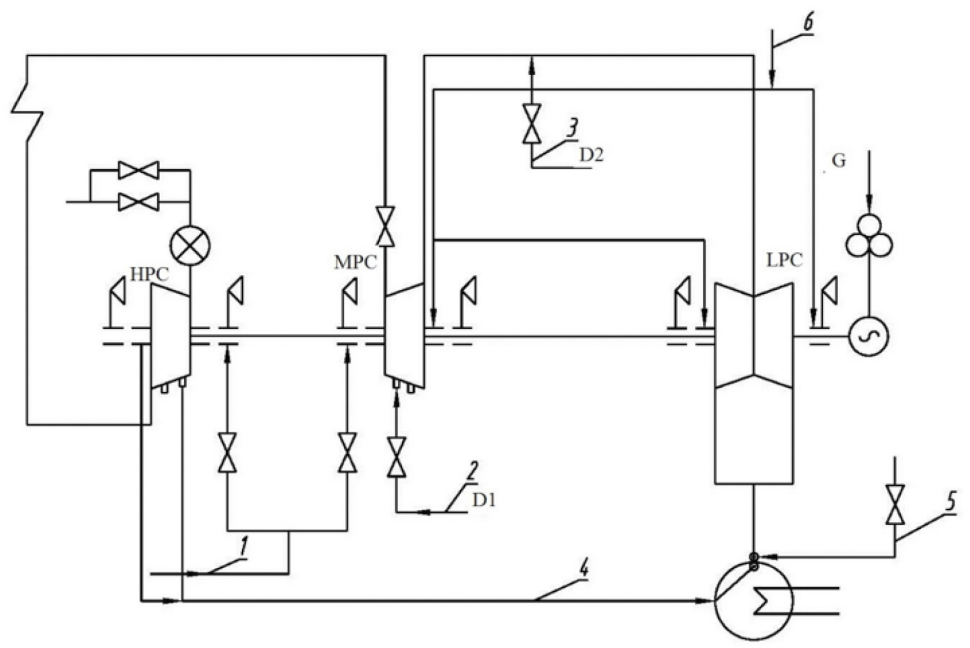

Figure 1: $\quad$ Simplified scheme of steam supply for transfer of turbine K-200 into GDM. 1. Steam supply to the front line of the end seals HP Cylinder and MP Cylinder. 2. Cooling steam supply line to MP Cylinder. 3. Cooling steam supply line to LP Cylinder. 4. Steam reset line from 1 selection HP cylinder to the condenser. 5. Condensate supply line. 6 . Steam supply to the rear line of the ends seals HP Cylinder and MP Cylinder.

At backup time equal to 6-8 the value of power consumption in case of GDM at power units with output 100,160,200, 300 and $800 \mathrm{MW}$ is lower, than with the use of alternative ways of control the daily schedules of electrical load (mode of minimum load, shutdown-startup) [1]. 
Table 1: Based on the conducted research Table 1 shows some data, characterizing GDM at high output power units.

\begin{tabular}{|c|c|c|c|c|c|c|c|}
\hline \multirow{2}{*}{ № } & \multirow{2}{*}{ Value } & \multirow{2}{*}{ Units } & \multicolumn{5}{|c|}{ Turbine type } \\
\cline { 4 - 8 } & & & $\mathrm{K}-100$ & $\mathrm{~T}-100$ & $\mathrm{~K}-200$ & $\mathrm{~K}-300$ & $\mathrm{~K}-800$ \\
\hline 1 & $\mathrm{Nmp}$ & $\mathrm{MW}$ & 1.65 & 1.85 & 2.6 & 4.2 & 20.0 \\
\hline 2 & $P_{k}$ & $\mathrm{MPa}$ & 0.004 & 0.006 & 0.005 & 0.004 & 0.005 \\
\hline 3 & $D_{1}$ & $\mathrm{~kg} / \mathrm{s}$ & 0.70 & 1.50 & 3.00 & 6.00 & 24.00 \\
\hline 4 & $D_{2}$ & $\mathrm{~kg} / \mathrm{s}$ & - & - & 0.85 & 3.0 & 6.0 \\
\hline 5 & $G_{B \Pi}$ & $\mathrm{kg} / \mathrm{s}$ & 4.10 & 5.00 & 8.00 & 12.0 & 24.0 \\
\hline 6 & $\tau$ & $\mathrm{min}$ & $15-20$ & $20-30$ & $20-30$ & $30-40$ & $40-50$ \\
\hline 7 & $B_{M P}^{\text {OITT }}$ & $\begin{array}{c}\text { ref. f. t/h } \\
\text { ref.f kg/s }\end{array}$ & $\begin{array}{c}1.04 \\
0.29\end{array}$ & $\begin{array}{c}1.15 \\
0.32\end{array}$ & $\begin{array}{c}2.51 \\
0.695\end{array}$ & $\begin{array}{c}4.30 \\
1.194\end{array}$ & $\begin{array}{c}25.3 \\
7.02\end{array}$ \\
\hline
\end{tabular}

\section{Implementation of GDM at steam turbines of CCGT}

In course of operation of modern combined cycle gas turbines (CCGT) the problems were found, which are specific for equipment of CCGT-450 at partial loads [11]:

- decrease of reliability of steam turbine operation at the steam temperature values in $\mathrm{HP}$ conduit lower than $450-460^{\circ} \mathrm{C}$ due to the increase of hyperadmissible final steam humidity in the area of last stages of LP cylinder;

- deterioration of ecological parameters when GT loads decreases below 85 MW (56.7\% of maximum GT output), due to the fact that in ПЕГ combustion chamber the technological transition occurs from the mode of preliminary mixing to the diffusion mode of combustion, which leads to sharp growth of nitrogen oxides concentration, and below the load of 60 $\mathrm{MW}$ - also the $\mathrm{CO}$ concentration in fume gases increases;

- decrease of CCGT economic feasibility with its operation at smaller loads is conditioned by two factors - decrease of GT efficiency due to increase of load share consumed by compressor and decrease of steam turbine efficiency due to the decrease of HP steam temperature.

Based on the conducted research the control range for CCGT-450, as the function of outdoor air temperature, with the limit of HP steam temperature $t_{0 в д ~}=460{ }^{\circ} \mathrm{C}$, may be presented in the form of regressive equation:

$$
\Delta N_{\text {РД }}=\left(\frac{199.4-3.113 t_{H B}+0.051 t_{H B}^{2}}{1-0.0172 t_{H B}+0.000578 t_{H B}^{2}}\right) .
$$


Analysis (5) shows that the control range of CCGT-450 when the outdoor air temperature changes in rather wide limits - its maximum value reaches $202 \mathrm{MW}$ at outdoor air temperature approx. $(-0.5)^{\circ} \mathrm{C}$, and at temperatures $(-30)^{\circ} \mathrm{C}$ and $+30^{\circ} \mathrm{C}$ it decreases for $34.9 \mathrm{MW}$ and $50.1 \mathrm{MW}$ respectively.

Thus, the control range of CCGT-450 is in the limits $38-41 \%$ from maximum load, which is considerably weaker than the similar parameter of condensation type power units working on gas-oil residue fuel, which shows the need to develop the process solutions, which allow for expansion of the CCGT control range.

Another peculiarity of CCGT is in the fact that the parameters of maneuverability of gas turbines and steam turbines differ a lot between each other. Thus, after night stopover the gas turbine is started within 10-15 minutes, however the start of steam turbine happens within 60-65 minutes. This leads to the fact that during backup of CCGT output by means of CCGT stopover as a whole or only one as turbine stop the overall length of start is mostly determined by the time required to start the steam turbine. Moreover, the compulsory discharge of steam from heat recovery steam generator to condenser due to nonavailability of steam turbine results in considerable heat and fuel losses during startup.

These deficiencies while CCGT output backup may be eliminated by transferring the steam turbine into GDM with all the advantages, typical for this mode [12].

When CCGT-450 operates in condensation mode the GDM of steam turbine may be used when stopping CCGT into backup mode as a whole, as the alternative to turbine stopover. When this unit operates in the heat-extraction mode the turbine GDM may be used for deep unloading of CCGT by maximum unloading of gas turbines considering the above limitations on their minimum load and by transition of steam turbine into GDM, and the HP and LP steam produced in heat recovery steam generators may be used to ensure the heat load of CCGT. If it is required to decrease the pressure of HP and LP steam down to the required values for outlet $\mathrm{DH}$ water temperature respectively from $\mathrm{DH}$ water heaters of high and low pressure it is required to install the relevant pressurereducing desuperheating stations at the lines of HP and LP steam supply to grid heaters.

Figure 2 shows the principal diagram of T-150-7 turbine transition into GDM.

The procedure of T-150-7 turbine transition into GDM, when CCGT-450 operates in heat-extraction mode is as follows:

1. CCGT is unloaded down to minimum allowable load, determined based on (5); when CCGT operates in heat-extraction mode the degree of unloading for both gas turbines or shutdown of one of them will depend on the value of CCGT thermal load.

2. DH water heaters will shift to the corresponding pressure reducing and desuperheating device and the supply of live (operation) steam is stopped into turbine without disconnection of generator from grid. 


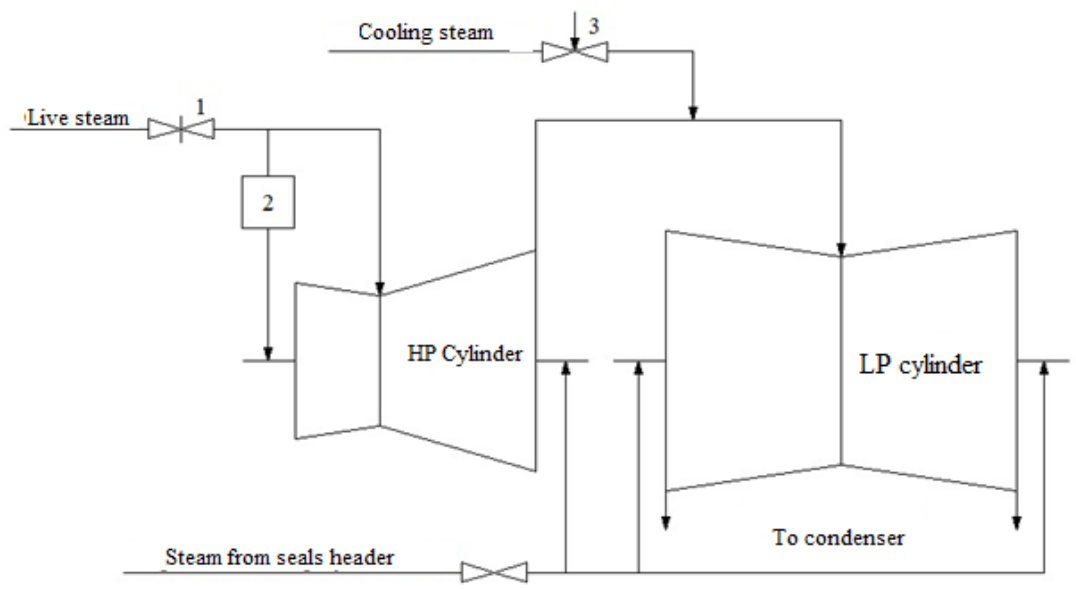

Figure 2: Scheme of steam supply during operation of T-150-7,7 turbine in GDM. 1. Throttling valve of HP cylinder; 2. Pressure reducing and desuperheating unit; 3 . Control valve.

3. As a result of synchronous operation of generator with grid it transits into the mode of engine (motor), consuming the power from grid.

4. Normal vacuum is kept in the turbine condenser.

5. The required amount of live steam is supplied to the front end seals (with temperature $160-220^{\circ} \mathrm{C}$ ) and to inlet of $\mathrm{HP}$ cylinder (pressure $0.1 \mathrm{MPa}$, temperature $450^{\circ} \mathrm{C}$, maximum flow rate $-0.30 \mathrm{~kg} / \mathrm{s}$ ).

6. Steam from the sealing steam header (temperature $160-180^{\circ} \mathrm{C}$ ), is supplied to the end seals of HP cylinder and to seals of LP cylinder.

7. To HP cylinder inlet the cooling steam is supplied from the steam supply line to $\mathrm{DH}$ water heater 2 on the nearby turbine (pressure $0.1 \mathrm{MPa}$, temperature $100^{\circ} \mathrm{C}$, maximum flow rate $-0.3-3.33 \mathrm{~kg} / \mathrm{s}$ depending on the pressure in the condenser).

8. To stabilize the temperature condition of the last stages of LP cylinder it is required to use the condensate injection system.

9. Such arrangement of steam supply into turbine provides for deviation of metal temperature of turbine stages, operating in GDM, for not more than $35^{\circ} \mathrm{C}$ as compared with the temperature of the nominal mode (Figure 3 ).

Such temperature condition of turbine allows for accelerated start of steam turbine within 10-15 minutes. Moreover, when starting CCGT from the stop state the steam produced by heat-recovery steam generator may be directed into steam turbine in the LP steam line and in the additional line of GDM cooling steam supply, which will permit to substantially decrease the startup losses of CCGT. 


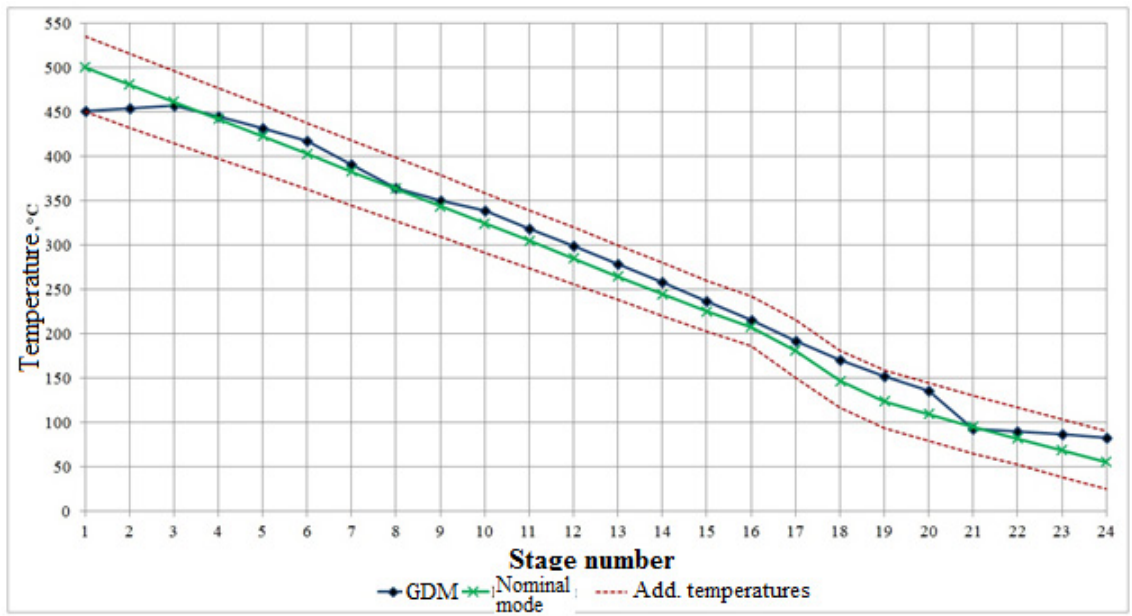

Figure 3: Temperature spread in the flow part of T-150-7 turbine in GDM.

\section{Conclusion}

So, the use of GDM at steam turbines of all types as the way for power backup for times of scheduled electrical load failures has, as compared with SSM a series of operation advantages: considerable increase of maneuverability and reliability of equipment during operation in semi-peak mode; service period of elements increases due to the minimum amplitude of thermal tensions during the whole cycle of load change; cyclic temperature tensions decrease, which removes the limitations on the amount of transitions of turbine unit into the backup mode.

The usage of GDM at steam turbines of TPP and CCGT is feasible for the following purposes:

- $\quad$ to identify the way of control the daily schedules for electrical load to ensure the ultimate maneuverability and maximum control range of power plants;

- to leave the turbine unit in the condition of hot rotating backup in the periods of minimum electric power consumption, and turbogenerator - as the synchronous compensator;

- $\quad$ to transfer the turbogenerators of power plants to GDM instead of short term stopovers and starts when the emergency protections are engaged;

- $\quad$ to use GDM of separate cylinders of turbine to improve the power unit start process;

- $\quad$ to extend the terms of active service of turbines and power units in general. 


\section{References}

[1] Arakelyan E.K., Starshinov V.A. Increase of profitability and maneuverability of the equipment of thermal power plants. M.: MEI Publishing House, 1993.

[2] Madoyan A.A., Levchenko B.L., Arakelyan E.K., et al. Application of GDM at thermal power plants. M.: Energy, 1980.

[3] Bjoorgard A.B. Economic problems in connection with production reactive power. CIGRE, Report and Power, 1962, No. 109.

[4] Kulichikhin V.V., Gutorov V.F. Use of GDM of turbine units on thermal power plant. M.: SPO ORGRES, 1977.

[5] Kapelovich D.B., Kobzarenko L.N., Baltyan V.N., et al. Research of the scheme and technology of GDM of turbine K-160-130. Power Plants, 1987, No. 7.

[6] Madoyan A.A., Kobzarenko L.N. About feasibility of GDM at turbine units of the NPP. Power System, 1986, No. 3.

[7] Oprev M., Wrang J., Arakelyan E.K., et al. Estimation of economic efficiency of large turbine generators in a synchronous compensator mode.

[8] Powell E.B. Sunehernenos, Condensos operation of turbogenerators. CIGRE, Report and Power, 1960, No. 16.

[9] Arakelyan E.K., Ilyin E.T. About the generator driving mode at turbine units with supercritical parameters of steam. Thermal Engineering, 1990, No. 5.

[10] Trukhny A.D., Kobzarenko L.N., Madoyan A.A., Arakelyan E.K., et al. Low-cyclic reliability of rotors of K-200-130 turbine at various ways of their transition into night backup. Power System, 1982, No. 10.

[11] Arakelyan E.K., Andryushin A.V., Burtsev S.Yu., Andryushin K.A., Hurshudyan S.R. Methodical provisions of the accounting of features of CCGT at optimum distribution of thermal and electric loads of combined heat and power plant with the complex structure of equipment. Power System, 2015, No. 5, pp. 1-5.

[12] Arakelyan E.K., Andryushin K.A., Bezdelgin I.Yu. Research of a temperature condition of flowing part of T-125/150 steam turbine during its work in the steam-less and GDM modes. Power Plants, 2015, No. 6, pp. 21-26. 